\title{
Emotional Istinct System and Mathematicals Law: Predominace and Submission
}

\author{
Luisetto $\mathrm{M}^{1^{*}}$, Oleg yurevich latyshew ${ }^{2}$
}

${ }^{1}$ IMA academy ICT and organizative and management branch, Applied pharmacologist, Italy 29121

${ }^{2}$ President IMA Academy

\begin{abstract}
Mathematica law must be uploaded whit a new discipline named EMOTIONAL mathematics that follow principles of the EMOTIONAL SYSTEM of animal world.
\end{abstract}

Observing various scientific discipline is possible to produce a global theory.

Corresponding author: Luisetto M, IMA academy ICT and organizative and management branch, Applied pharmacologist, Italy 29121. E-mail: maurolu65@gmail.com

Received: February 14, 2020 Accepted: February 21, 2020, Published: February 25, 2020

Keywords: Mathematical Law, Emotional System, Instict,Algorithm, Dimension,Imputs, Results, Interference, Predominace, Submission, Priority Law, Evolutionary, Kinetics , Saturation

\section{Introduction}

\section{Material and Methods}

Observing some scientific discipline various mathematical principles link different parameter in order to produce derived dimension and value. But is interesting in this discipline to observe also some HUMANS way of thinking and related biological Way of translate, starting from BRAIN, in some relevant response related specific kind o stimuli.

The same stimuli can produce in the same individuals real different response : in example during and emotional storm in few seconds is really different vs a situation long 1 hour and not dangerous for the individual. So is possible to say that input and output use and algorithm with 2 o more sub way related the different condition.

But this depend on the functionality of a system, a system very ancient in evolution (archeo brain or reptile brain) [1]. In this system in order to have a really rapid and efficient response related a dangerous or letal stimuli is request a instantaneous response without a CORTEX control.

This ancient system is today present also in evoluted humans because high efficient. Not a rational response but the right efficient response in a little amount of time. Even the most rational individuals in letal dangerous condition in few seconds can change its destiny and shift form a rational response to an other even irrational but safety for him response. In 
this apparatus an mathematical function make possible this physiologic change.

In this process is possible on the contrary to think to a way to explain in mathematical way this concept:

EMOTIONAL process must be introduced in mathematical science in order to better link human thinking whit Computer Science.

In a simply way is possible to write: the general principle $\mathrm{A}$ Function $B$ to have affect A,B, C, et other

Can become A function (EMOTIONAL translation- interference) B to have really different kind of response: $A, B, C$ et other. The EMOTIONAL interference is a new kind of function and follows other mathematical principle unknown.

The function of this Interference - Transaltion System seem to follow different mathematical law

And in low level of stimulation this follows a direct relationship, but if it change little the stimuli over a basal system level other relationship appear: a complete EMOTIONAL STORM that provide a unique response attach and escape reaction typical of reptile brain.

This happen not related to a logarytmic way, but is clear that when the stimuli overload the system at this kind of level the system present a stop to the cortex for limited periods and the lymbic system prevail.

Observing literature related brain evolution of superior vertebrates is possible to verify that the more recent structure like CORTEX cover the more ancient brain part like reptilian brain.

But this 2 different system in evolution present 2 different scope ( cortex functions are really different from other brain part like reptilian brain) but coexist in every individuals But this kind of reaction happen related some kind of emotional response like fear, danger situation and other related but other EMOTIONAL SYSTEM can influence the global response .

Is possible to verify the EFFECT of LOVE in much human relationship. The same the mathematical relationship between 2 variables A Input and B FINAL EFFECT can be a complex formula and the FUNCTION that relate themselves this can be a COMPLEX formula. According evolutive approach is interesting to observe the sense of some kind of Emotional Sysem as Selective and efficient system to guarantee the re- production and to take care to the progenie. Evolution created the most sophisticate strategie to make this EMOTION one of the most crucial for surviving of many indivudals.

The same the life strategy of some kind of superior vertebrates: from hunting strategy, to strategy to find food, to the group dynamics and other needed various brain system to make possible that the individuals

Follows also the goals of the groups and not only the single individual need.

In all this situation, controlled by EMOTIONAL SYSTEM , various mathematical law are followed in order to Have the real useful result related crucial aspect of life : reproduction, food search, safe life, groups empowerment and many other

\section{Emotion List}

Fear $\rightarrow$ feeling of being afraid, frightened, scared.

Anger $\rightarrow$ feeling angry. A stronger word for anger is rage Sadness $\rightarrow$ feeling sad. Other words are sorrow, grief (a stronger feeling, for example when someone has died)

Joy $\rightarrow$ feeling happy. Other words are happiness, gladness

Disgust $\rightarrow$ feeling something is wrong or nasty. Strong disapproval.

Surprise $\rightarrow$ being unprepared for something.

Trust $\rightarrow$ a positive emotion; admiration is stronger; acceptance is weaker.

Anticipation $\rightarrow$ in the sense of looking forward positively to something which is going to happen. Expectation is more neutral

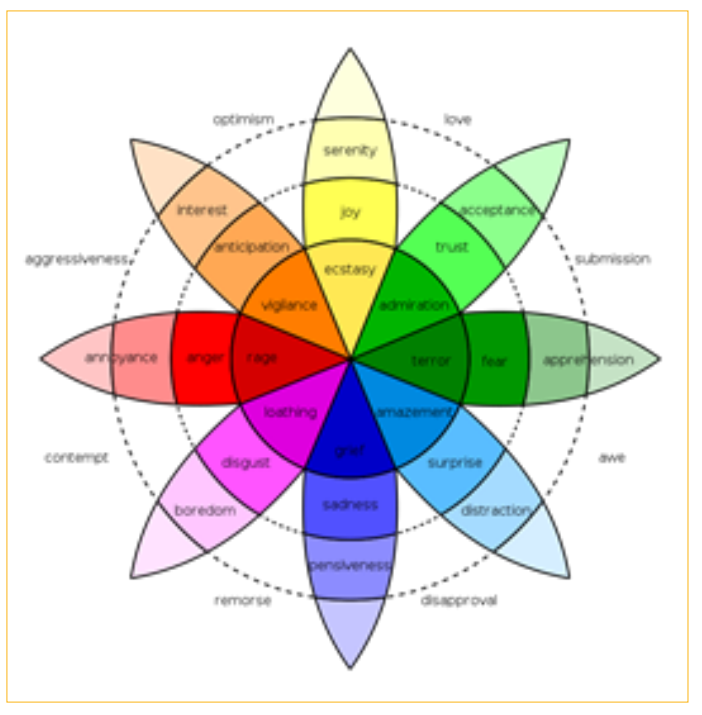

Figure1: Plutchik's Wheel of Emotions. 


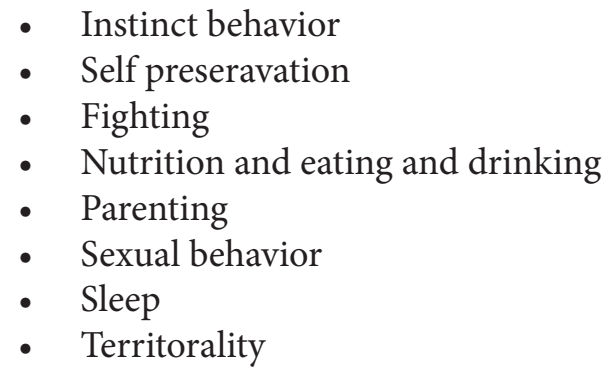

\section{Results}

Observing the literature reported in reference is possible to verify that related an equals level of stimuli very different response can be obtained related the emotional status of an individual and the Amygdala and limbic system.

In very dangeros situation to live or to dead depend on a very rapid decision in high stressant conditions.

The output change in high way: for this reason is interesting to find a mathematical relationship that can

Describe better this human condition.

The same also analyzing other HUMAN EMOTIONAL SYSTEM is interesting to observe how change the response to an input and are used DIFFERENT MATHEMATICAL RELATIONSHIP by the same brain in different condition.

This mathematical relationship present inside different TASK: self-saving life, reproduction, groups' dynanics, food search activities and other.

So related a Stimuli A: the final effect pass through a combination of different mathematical relationship

That follow many endopoint (a: self-save live, b: reproduction, c: food search, d: groups dynamics, e: danger situations and other).

But this system present priority way that change related the environment and situation. An useful function can be change whit another more useful in a new situation. Why a mother in order to save her pogenie can also scarify her life ? What kind of algorytm is used in this case? This new mathematical principle can be useful in next Computer science especially related the priority of choose.

\section{Discussion- Conclusion}

Related the literature reported and as global conclusion a new kind of mathematical relationschip between

2 elements linked by really different outcomes: a emotional mathematical function that recognize

Infinitesimal difference in stimuli and a really pervasive emotional storm as perturbating factor.

All this that take in consideration the imperative circuits of istincts ( in example self-save life and all other necessary to transfer genetic pathways in a new organism). Is superior vertebrates like mammalians take care of progenie is fundaments in their evolutive advantaged But this imply a more efficient emotional syste.

Mathematical law can be updated adding some principles for other discipline like physiology, pharmacology, kinetics, toxicology and principle related kinetics, dose responces, peak effect, logarithmic response, exponential effect, failure of the system, overload of stimuli and other.

This system related and input A to a final response B trought a real compex multiple function.

Various subfactors but contribute each one in different way : starting from a direct relationship to

Other and more complex system like on/ off system or saturation kinetics or global inhibition of other structure. All this can be translated in mathematical way in objective way. What is interesting is the real global efficacy of the system.

Perhaps it is for this reason that until today great famous innovative airplane fall dawn even if a modern software, and in other letal situation the human mind I few milliseconds take the right decision to safe many life. Mathematics science must also follow nature principle of life [2-7].

\section{Clarifications}

This work is produced only whit the scope to submit to researcher new methodological strategy useful in various settings in decisional field.

\section{References}

1. Amygdala (2016) pharmacology and crime behavior, dysfunctions to be considered as a disease? Luisetto $\mathrm{m}$ IABCR.

2. Mauro Luisetto (2017) Jurisdictional consequences in some Brain condition. Neuropharmacology Milan.

3. Mindset Kinetics and Crime Behavior- Quantitative Methods? A New Forensic Quantitative Approach. How Biochemistry, Toxicology, Imaging Principle can Help in Jurisdictional Settings 2019 DOI:10.34297/ ajbsr.2019.02.000563. 
Citation: Luisetto M and Oleg Yu Latyshev (2020) Emotional Istinct System and Mathematicals Law: Predominace and Submission. Journal of Economics \& Management Research. SRC/JESMR/106. DOI: doi.org/10.47363/JESMR/2020(1)103

4. Mauro Luisetto, Naseer Almukhtar, Ghulam Rasool Mashori, Behzad Nili Ahmadabadi, Ram Kumar Sahu (2019) Addiction and Evolutionary Process, Common Aspects in Physio-Pathologic Pathways Useful in PharmacoToxicological Approach Online Journal Of Neurology And Brain Disorders 2: 134-144.

5. The Evolution of the Nervous System: Invertebrates vs. Vertebrates a useful Instrument and Model to Research New Pharmacological Strategies in some Human Neurodegenerative Conditions

6. Mauro Luisetto, G Ibrahim et al 2019 AJBSR.

7. S Freud opera omnia.

8. k Lorentz opera omnia.

Copyright: (C)2020 Luisetto $M$. This is an open-access article distributed under the terms of the Creative Commons Attribution License, which permits unrestricted use, distribution, and reproduction in any medium, provided the original author and source are credited. 